\title{
Colon or Rectum Neuroendocrine Tumor pTO TNM Finding v7
}

National Cancer Institute

\section{Source}

National Cancer Institute. Colon or Rectum Neuroendocrine Tumor PTO TNM Finding v7. NCl Thesaurus. Code C90102.

Colon or rectum neuroendocrine tumor with no evidence of a primary tumor. (from AJCC 7th Ed.) 